\title{
Spatial Differentiation and Influencing Factors of the Green Development of Cities along the Yellow River Basin
}

\author{
Yu Chen, ${ }^{1}$ Xuyang Su, ${ }^{1}$ and Qian Zhou $\mathbb{D}^{2}$ \\ ${ }^{1}$ School of Economics and Management, Zhengzhou University of Light Industry, Science Avenue 136, Zhengzhou, \\ Henan 450000, China \\ ${ }^{2}$ Economics School, Zhongnan University of Economics and Law, Nanhu Avenue 182, Wuhan, Hubei 430073, China \\ Correspondence should be addressed to Qian Zhou; z0005072@zuel.edu.cn
}

Received 17 October 2021; Revised 21 December 2021; Accepted 17 January 2022; Published 8 February 2022

Academic Editor: Victor Shi

Copyright (c) $2022 \mathrm{Yu}$ Chen et al. This is an open access article distributed under the Creative Commons Attribution License, which permits unrestricted use, distribution, and reproduction in any medium, provided the original work is properly cited.

\begin{abstract}
The traditional development model of high consumption and low efficiency approaches the threshold of resource and environmental carrying capacity, bringing a series of severe social and ecological environmental problems, and it is urgent to realize green development transformation. Based on a multidimensional perspective, this paper constructed a comprehensive evaluation system for urban green development along the Yellow River Basin (YRB). Entropy method, exploratory spatial data analysis (ESDA) model, and trend analysis were used to measure and characterize the spatiotemporal evolution of urban green development index (UGDI) along the YRB in 2008, 2013, and 2018, and geographically weighted regression (GWR) model was used to explore the influencing factors of urban green development. The results are as follows: (1) the UGDI along the YRB showed a slow upward trend, but the absolute value was relatively low, mainly concentrated in $0.2699-0.3799$. (2) The UGDI had obvious regional differences, and cities such as Baotou and Zibo showed a "high-high" agglomeration, while most cities in the midstream showed a "low-low" agglomeration, and in terms of space, they were "high in the east and west, low in the middle" and "high in the north and low in the south." (3) Influencing factors had different degrees of impact on the UGDI. Economic, industrial, urbanization, and green infrastructure factors played a positive role in promoting the urban green development, while the relationship between governance, technological factors, and green development varies from city to city.
\end{abstract}

\section{Introduction}

The city is a highly concentrated area of people's life and production, and it plays the dual role of industrial development carrier and regional economic growth engine. With the continuous advancement of population urbanization and land urbanization, cities have accumulated a lot of material wealth, and the population size, spatial scale, and production scale have also been rapidly expanded, forming a new urbanization development path with distinct characteristics in China [1-3]. In 2020, 56.2\% of the world's population lived in urban areas, and it is expected that this proportion will increase to $62.5 \%$ by 2035 [4]. Sustained population growth, economic development, and resource consumption approach or exceed the ecological boundary, intensifying the contradiction between human and nature, environmental pollution and ecological destruction are becoming increasingly serious, the contradiction between supply and demand of natural resources is increasing, and human physical and mental health and social harmony are also threatened $[5,6]$. In the context of the gradual disappearance of labor factor dividends and the increasingly tense resource and environmental constraints, the development model that relies only on increasing inputs of production factors cannot be sustained [7]. At present, COVID-19 has swept the world and caused serious impact on the economic and social development of various countries. It is imperative to realize the transformation of thinking and economic growth model.

From a long-term perspective, green development is an effective way to cope with climate change and energy resource crises $[8,9]$. It is an inevitable choice for future 
development models. It can maintain a balance between economic growth, wealth accumulation, social development, and environmental protection and will help create a new situation of social material and ecological civilization and then realize the organic coordination of "production-livingecology." As an important ecological barrier and economic belt, the YRB is a typical area with rapid economic-societyenvironmental changes. Its green development is related to regional coordination and linkage and the establishment of a modern social and economic system. However, a series of factors such as long-standing rigid constraints of resources and environment, irrational industrial structure, and unbalanced spatial development have put a lot of pressure on ecological security in the basin, and the coordination among human being, nature, and society is facing huge challenges. In view of this, president $\mathrm{Xi}$ Jinping proposed to handle the relationship between ecological protection and high-quality development correctly and pointed out at the conference of the Central Finance and Economics Committee that the YRB must be vigorously protected and governed to take the path of ecological protection and high-quality development. Therefore, based on the research logic of "UGDI measurement-spatial and temporal pattern analysis-influencing factors analysis," this paper uses entropy method to calculate UGDI and then discusses the agglomeration characteristics of green development according to spatial pattern and spatial autocorrelation analysis. Finally, the GWR model is used to analyze the influencing factors of green development. The results are expected to provide reference for ecological protection and high-quality development in the basin. The structure of this paper is as follows: Section 2 is a literature review on the study of green development; Section 3 is a presentation of materials and methods; Section 4 is the results of this paper; and Section 5 is conclusions and suggestions. The research framework of this paper is shown in Figure 1.

\section{Literature Review}

2.1. Concept Definition. Green development is a critique of traditional development models [10] and also a deepening and improvement of concepts such as green economy, circular economy, and sustainable development [11]. With the development of industrial civilization and the accumulation of material capital, in order to alleviate the contradiction between economic growth and the ecological environment, early green development related ideas pointed out that it is necessary to move from growth fanaticism to a stable state and advocated investing in natural capital and fostering sustainable development of the environment [12]. Steady-state economy, green economy, and ecological economy are considered the original ideas of green development. The academic community widely believes that the research on green development or green economy started with Pierce's "Blueprint for a Green Economy." The book points out that economic development must be bearable by the natural environment and human beings themselves and will not blindly pursue production growth and cause social division and ecological crisis [13]. With the deepening of research, the concept of sustainable development was proposed and showed a certain comprehensiveness. Although sustainable development is a controversial concept, it is usually expressed as the intersection of environment, society, and economy, and the three should be unified on the path of sustainable development [14]. In addition, some scholars also defined green development from the perspective of ecological industry and believed that measures such as adjusting factor prices and differential taxes should be adopted to cultivate lowcarbon economy and green economy and establish a sustainable and circular development model [15]. On the whole, the research on green development shows a flourishing situation. Most scholars' understanding of green development mainly focuses on two viewpoints. One view holds that green development is to fully understand the interaction mechanism of economic, social, and natural system under the constraints of resources and environment and finally realize the maximization of the benefits of the three systems [7]. Another view emphasizes that green development is the pursuit of coordination between economic development and ecological environment [16].

2.2. Index System and Evaluation Methods. The establishment of an evaluation index system for green development and quantitative analysis of the status of green development can provide an important basis for government decisionmaking and improvement of management efficiency. Some organizations and scholars have carried out a large number of studies on green development evaluation index systems and measurement methods [17-19]. In terms of the construction of the indicator system, the OECD places more emphasis on the positive role of economic growth in tackling climate change and environmental protection, defines green development from the perspective of green growth, and then proposes four primary indicators including economy, environment, society, and technology and development, and the corresponding green growth indicator system of 14 secondary indicators. Although UNEP's inclusive green economy measurement indicator system has similarities with the OECD, it places more emphasis on ecological protection [20]. Based on the research theory and practice state of China's green development, some scholars have established a national and regional green development evaluation index system, such as the establishment of the China green development index to evaluate the status of green development in various areas in China [21], and constructed a green development evaluation system according to the connotation of China's green development in the new era [22], and a regional green development evaluation index system was constructed from the dimensions of ecological space optimization, good ecological environment, and ecological economic development [23]. The early evaluation methods were mainly based on the DEA model. For example, Färe et al. [18] measured the environmental efficiency index of OECD countries, and Coli et al. [17] measured the environmental efficiency of Italian provinces in 2004. Since then, TOPSIS model, projection pursuit model, comprehensive index method, spatial measurement model, information entropy model, and dissipative structure theory have also been more and more popular [22]. 


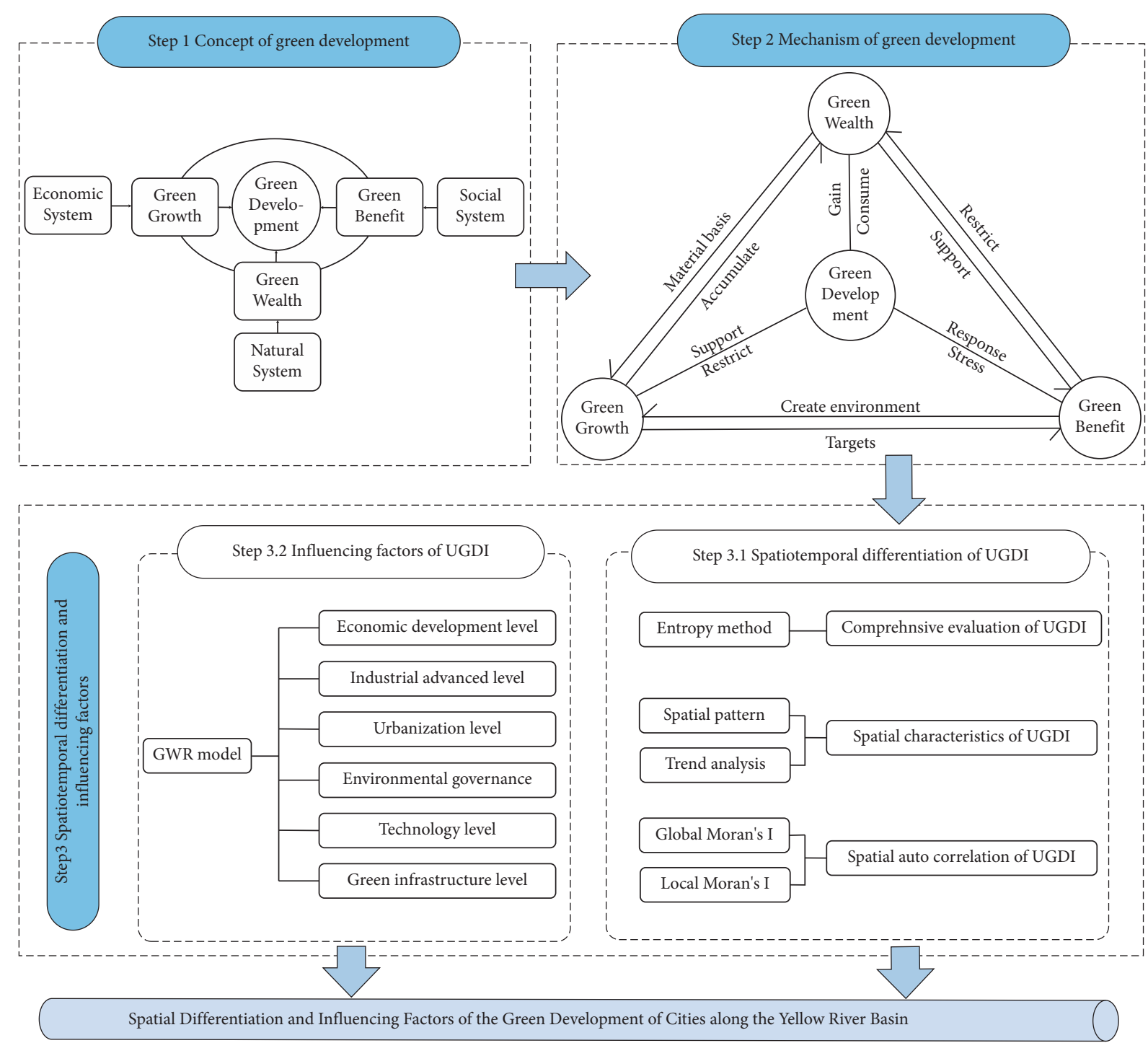

FIGURE 1: Research framework.

2.3. Factors Affecting Green Development. The research on the influencing factors of green development is helpful to distinguish the degree of influence of each influencing factor, and it can also provide a certain reference for policy making to improve the green development level. Shironitta's inspection and calculation analysis of carbon dioxide emissions from 1995 to 2009 in 40 countries found that the deindustrialization of high-income countries has resulted in lower $\mathrm{CO}_{2}$ emissions than middle-income countries with heavy industrial and believed that changes in industrial structure are an important factor affecting economic green development [24]. Honma and $\mathrm{Hu}$ [25] found that a higher proportion of manufacturing and wholesale and retail will reduce the efficiency of green development. However, the overall industrial development or the improvement of the green development level is affected by technology, and technological progress promotes the continuous development of human society. Whether in traditional OECD countries or newly industrialized countries, general technological innovation and specific technological innovation are conducive to the country's green and sustainable development. Especially with the transition of energy development from the "oil era" to the "low carbon era," how to balance economic development and energy utilization to improve the green development level is a major practical issue facing today. In addition, some scholars have tried to propose a path to achieve green development in terms of key measures, policy support, institutional guarantees, and promotion mechanisms [26] and believe that it is necessary to coordinate interest relationships, regulate the behavior of subjects, improve institutional arrangements, and promote encouragement compatibility and other aspects to promote the green development [27].

To sum up, green development is the focus of attention of all countries in the world today. It has gone through a process from shallow to deep, from single to diversified, and there is a trend of refinement to specific industries and regions, but there are still issues that need to be explored in 
depth. In terms of evaluation indicators, the trend of multidisciplinary cross-analysis based on a certain framework structure has emerged. Although the indicator system of green level and efficiency evaluation is relatively comprehensive, there is still room for improvement. For example, tolerance and equity are one of the goals of human development, and it is also the inherent requirement of green development, but the evaluation system of existing research pays little attention to this aspect. In terms of influencing factors, although many scholars have conducted research from a qualitative and quantitative perspective, fewer spatial analysis methods have been used. Therefore, in terms of research content, this paper breaks through the previous single mode of thinking and integrates economic, social, and natural system to carry out multilevel research on green development level; uses entropy method, ESDA model, and other methods to quantitatively study the spatiotemporal pattern of the green development; and seeks a path to achieve green development through the GWR model, to a certain extent to make up for the lack of discussion of regional differences in previous studies.

\section{Materials and Methods}

\subsection{Concept and Theoretical Basis}

3.1.1. Concept of Green Development. Under the constraints of resources and environment, green development focuses on maximizing environmental, economic, and social benefits in the development process through policy guidance, innovation-driven, and effective allocation of resources, so as to achieve the symbiosis of economic, social, and natural system and the diversification of development goals. On the basis of the existing research, the economic, social, and natural system are integrated to sort out the theoretical framework of green development (Figure 2). The framework consists of three levels: "core layer-middle layer-outermost layer." (1) The outermost layer is composed of economic system, social system, and natural system. The three systems are supported by different green concepts to form the foundation for green development. For example, in the economic system, the idea of low-carbon and recycling requires optimizing the industrial structure, reducing the consumption of energy resources, and forming a green development pattern of industrial agglomeration and technological innovation. In the social system, emphasis is placed on building green and smart cities and increasing fiscal policy support to increase people's well-being, improve people's living standards and social security, and achieve green social systems. Based on the basic pattern of ecological environment and natural characteristics, the natural system forms a green development benchmark by the interaction and coupling of natural factors such as water resources, land resources, and climate conditions. (2) The middle layer is the green performance of the economic, social, and natural system, which are represented as green growth, green benefit, and green wealth. Among them, green growth is the method, green wealth is the foundation, and green benefit is the goal. The three embody the core elements of green development. (3) The core layer is green development, which is formed under the combined effect of the outermost layer and the middle layer.

3.1.2. Mechanism of Green Development. Based on the understanding of the green development concept, this paper constructs a mechanism model with green development as the core and composed of green growth, green wealth, and green benefit (Figure 3). It can be seen from the above analysis that the economic, social, and natural system take green growth, green benefit, and green wealth as the development direction respectively. Under the concept of green development, the economic system is represented as green growth, the social system is represented as green benefit, and the natural system is represented as green wealth. On the interaction of outer circle, green growth relies on green wealth to provide the material foundation, continuously create social and economic benefits, and promote the accumulation of green wealth and improvement of the green benefit level. Green benefit is the goal of green growth, while the improvement of green benefit is restricted by green wealth. Once green benefit surpasses the boundary of green wealth carrying capacity, it will cause damage to the natural system. Green wealth is the long-term accumulation result of green growth. On the function of the inner circle, green development is at the core position. The positive interactions of green development to green growth, green benefit, and green wealth are shown in "support-response-gain," and negative interactions are shown in "restrict-stress-consume." In addition, in order to realize the coordinated and orderly operation of the three systems, it is necessary to build a green governance system led by the government, social collaboration, and public participation; it is a governance behavior aimed at ecological destruction and environmental pollution caused by negative interactions. Also, it is a guarantee for green development and further affects the performance of green growth, green benefit, and green wealth. Therefore, green development is a sustainable development that is based on the coordination and symbiosis of economic, social, and ecological systems, with green growth, green benefit, and green wealth as its connotation and green governance as its guarantee. This paper conducts research based on the above connotation and mechanism analysis.

\subsection{Methods and Index System}

\subsubsection{Research Methods}

(1) Entropy Method. Entropy method is an objective comprehensive evaluation method, which determines the index weight coefficient according to the amount of information provided by each index observation value. The higher the order of a system, the greater the information entropy and vice versa. The principle is to use information entropy to calculate the entropy weight of each index according to the variation degree of each index, to correct the weight of each index and obtain a more objective index weight, which can 


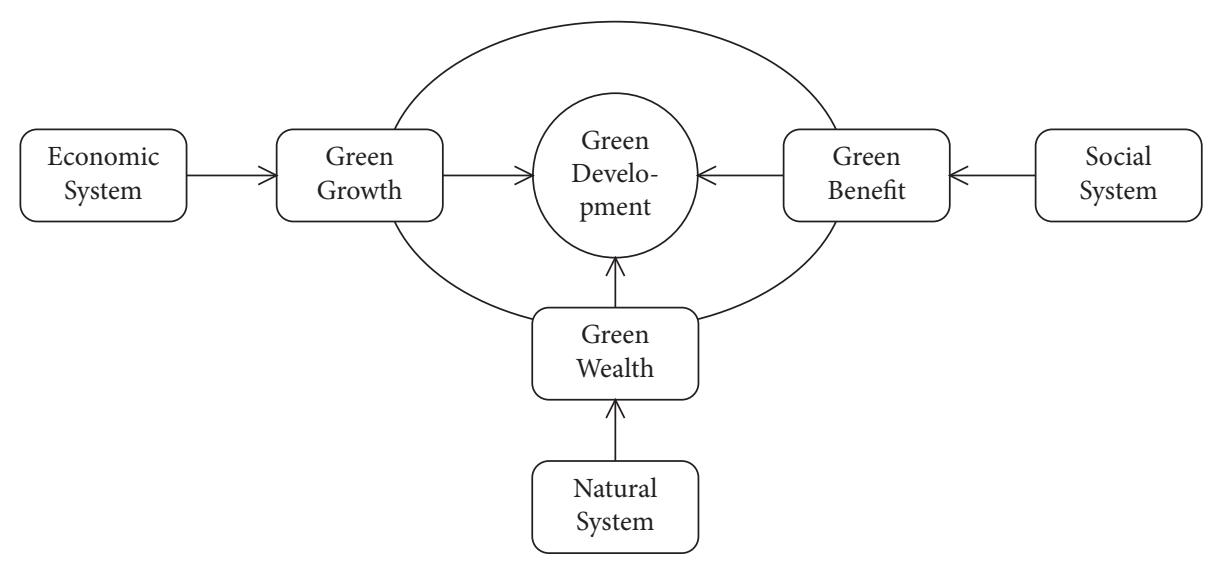

FIgURE 2: Concept framework of green development.

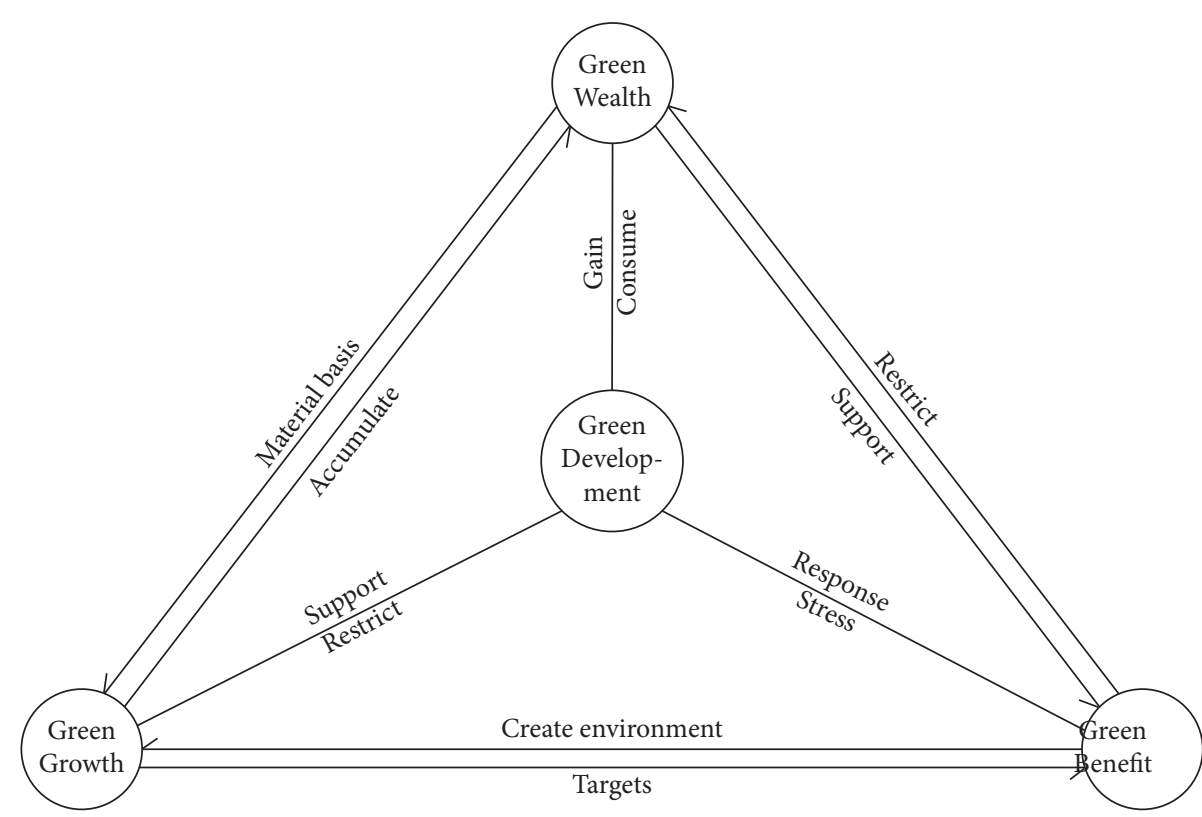

FIGURE 3: The green development mechanism of cities along the YRB.

also avoid human interference and has high credibility and accuracy $[28,29]$. To avoid negative values of standardized values and better reflect the role of reverse indicators, the extreme value method is used to standardize the data.

(1) Standardize the indicators:

Positive indicator:

$$
x_{i j}^{\prime}=\frac{x_{i j}-\min \left(x_{i j}\right)}{\max \left(x_{i j}\right)-\min \left(x_{i j}\right)} .
$$

Negative indicator:

$$
x_{i j}^{\prime}=\frac{\max \left(x_{i j}\right)-x_{i j}}{\max \left(x_{i j}\right)-\min \left(x_{i j}\right)},
$$

where $x_{i j}$ is the original value of the $i$-th evaluation object corresponding to the $j$-th index; $x_{i j}^{\prime}$ is the standardized value; $\max \left(x_{i j}\right)$ and $\min \left(x_{i j}\right)$ are the maximum and minimum values of each index respectively.

(2) Calculate the entropy value of the $j$-th index:

$$
e_{j}=-\mathrm{k} \sum_{i=1}^{m} P_{i j} \ln P_{i j} \text {, }
$$

where $k=1 / \ln (35), P_{i j}=x_{i j}^{\prime} / \sum_{i=1}^{m} x_{i j}^{\prime}$.

(3) Determine the index weight:

$$
w_{j}=\frac{d_{j}}{\sum_{j=1}^{n} d_{j}},
$$

where $d_{j}=1-e_{j}$.

(4) Calculate the comprehensive index of green development:

$$
Y_{i}=\sum_{j=1}^{n} w_{j} \times x_{i j}^{\prime}
$$


where $i=1,2, \ldots, 35 ; j=1,2, \ldots, 23 . Y_{i}$ is the UGDI, $w_{j}$ is the index weight, $x_{i j}^{\prime}$ is the standardized value, $i$ is the city, and $j$ is the index. According to the research of other scholars [23], this paper divides the UGDI into the following: $Y_{i}>0.5000$ indicates that the UGDI is at a high level, $0.3000^{<} Y_{i}^{<} 0.4999$ indicates that UGDI is at a medium level; $Y_{i}^{<} 0.2999$ indicates that UGDI is at a low level.

(2) Spatial Autocorrelation. Spatial autocorrelation analysis includes global spatial autocorrelation and local spatial autocorrelation analysis, which is used to explain the correlation and difference degree of a certain spatial attribute of the whole or adjacent units within the area. The Moran's I and Local Moran's I indexes are used for analysis respectively. The global Moran's I index formula [30] is as follows:

$$
\mathrm{I}=\frac{n \sum_{i=1}^{n} \sum_{j=1}^{n} W_{i j}\left(x_{i}-\bar{x}\right)\left(x_{j}-\bar{x}\right)}{\sum_{i=1}^{n} \sum_{j=1}^{n} W_{i j} \sum_{i=1}^{n}\left(x_{i}-\bar{x}\right)^{2}}
$$

where $n$ represents the number of spatial units in the study area, $i$ and $j$ are two different spatial units in the area, and $x_{i}$ and $x_{j}$ are values of spatial attributes $x$ in units $i$ and $j$ respectively. $W_{i j}$ represents the spatial weight matrix. If $i$ and $j$ are adjacent, $W_{i j}=1$; if not, $W_{i j}=0 . \bar{x}$ is the mean value. The value range of $I$ is $[-1,1]$. When $I>0$, it means spatial correlation is positive. The larger the value, the more obvious the spatial correlation is, and vice versa. When $I=0$, there is no spatial autocorrelation. A $Z$ test is required for Moran's I. The formula [31] is

$$
\mathrm{Z}(\mathrm{I})=\frac{\mathrm{I}-\mathrm{E}(\mathrm{I})}{\sqrt{\operatorname{Var}(\mathrm{I})}},
$$

where $E(I)$ and $\operatorname{Var}(I)$ are mathematical expectation and variance of Moran's $I$, respectively. When $Z(I)>0$ and significant, there is a positive spatial autocorrelation and vice versa. When $Z(I)=0$, there is no spatial autocorrelation.

To clarify the specific location of spatial agglomeration of high-level and low-level UGDI within the YRB, we use the local Moran's I index to identify the local spatial autocorrelation characteristics of green development. The formula [32] is as follows:

$$
I_{i}=\frac{\sum_{i=1, j=1}^{n} W_{i j}\left(x_{i}-x\right)\left(x_{j}-x\right)}{S^{2}},
$$

where $I_{i}$ is the local Moran's $I$ index of the $i$-th city and $S^{2}=(1 / n) \sum_{i=1}^{n}\left(x_{i}-\bar{x}\right)^{2}$; the results also need to be $Z$-tested, as in the formula above. At a certain level of significance, according to the significance level of the Moran's I index and the results of the $Z$ test, the research cities can be divided into four agglomeration relationships: (1) When Moran's $I$ is significant, positive, and $Z(I)>0$, it is a "high-high" $(\mathrm{H}-\mathrm{H})$ agglomeration relationship, and the UGDI of the research city and neighbouring cities is high; (2) when the Moran's I index is significant, positive, and $Z(I)<0$, it is a "low-low" (L-L) agglomeration relationship, and the UGDI of the research city and neighbouring cities is low; (3) when the
Moran's $I$ index is significant, negative, and $Z(I)>0$, it is a "high-low" (H-L) agglomeration relationship, the UGDI of the research city is high, and the UGDI of the neighbouring unit is low; (4) when the Moran's $I$ index is significant, negative, and $Z(I)<0$, it is a "low-high" $(\mathrm{L}-\mathrm{H})$ agglomeration relationship, and the UGDI of the research city is low, and the UGDI of the neighbouring cities is high. When $Z(I)=0$, it is randomly distributed.

(3) Geographically Weighted Regression. The essence of geographically weighted regression is local regression [33], which is solved by local weighted least squares method, where the weight is the distance function between the geographic location of the point to be estimated and the other observed geographic locations. These parameter values estimated at various geographic spatial locations describe the changes of the parameters with geographic spatial locations and are used to explore the nonstationarity of the regression coefficient space. The model structure is

$$
y_{i}=\beta_{0}\left(u_{i}, v_{i}\right)+\sum_{j=1}^{n} \beta_{j}\left(u_{i}, v_{i}\right) x_{i j}+\varepsilon_{i},
$$

where $i=1,2, \ldots, m ; j=1,2, \ldots, n, y_{i}$ is the value of the dependent variable at the geographic location $\left(u_{i}, v_{i}\right),\left(u_{i}, v_{i}\right)$ is the geographic center coordinate of the sample spatial unit, $\beta_{0}\left(u_{i}, v_{i}\right)$ is the constant value at the geographic location $\left(u_{i}, v_{i}\right), \beta_{j}\left(u_{i}, v_{i}\right)$ is the spatial value of the function $\beta_{j}\left(u_{i}, v_{i}\right)$ at the position of $i$ sample, and $\varepsilon_{i}$ is the residual. This paper uses the AICc method to determine the optimal bandwidth and then builds a GWR model for the green development level of cities along the YRB to conduct simulation, analysis, and discussion based on the simulation and model test results.

3.2.2. Construction of Index System. Green growth is mainly manifested in the development methods and concepts of low carbon, environmental protection, and green recycling, that is, to achieve green growth by reducing environmental pollution and reducing energy and resource consumption [7]. Based on the above analysis, the GDP per capita is used to measure the city's green development potential; the proportion of tertiary industry in GDP is used to reflect the degree of optimization of the city's economic structure; sulfur dioxide emissions per unit of GDP, smoke (powder) dust emission per unit GDP, and wastewater discharge per unit GDP are used to measure the degree of urban economic green growth.

Green welfare is mainly manifested in improving social welfare and enhancing people's well-being. It is the goal of green growth, which is embodied in residents' lives and science, education, culture, and health. Based on the above analysis, the disposable income of urban residents per capita is used to reflect the living standards of the people in general; the retail sales of consumer goods per capita are used to reflect the quality of life of urban residents, the proportion of science and education expenditures in GDP, the number of college students per 10,000 people, and the books in public 
libraries per 100 people; the number of medical beds per 10,000 people in a city measures the development of science, education, culture, and health in the city.

Green wealth is mainly reflected in sufficient green resources and good environmental quality, to improve people's living environment and achieve the development goals of resource conservation and environmental friendliness [34]. Based on the above analysis, the park green area per capita and the green coverage rate in built-up areas are used to measure the green space owned by urban residents; the number of days with good air quality in built-up areas, industrial wastewater discharge per capita, and industrial sulfur dioxide emissions per capita are used to measure the urban environmental quality.

Green governance is mainly manifested in pollutant governance, waste recycling, and infrastructure construction, building a green governance system guided by the government and people participating $[35,36]$. Based on the above analysis, use the centralized treatment rate of urban domestic sewage, the harmless treatment rate of urban domestic waste, and the comprehensive utilization rate of general industrial solid waste to measure the degree of recycling of urban resources. The urban road area per capita, the buses per 10,000 urban residents, urban water penetration rate, and the urban gas penetration rate reflect urban infrastructure construction. The index system is shown in Table 1: "+" represents positive index and "-" represents negative index.

3.3. Study Area and Data Sources. The Yellow River is the second longest river in China. It originates from the Bayan Har Mountains in Qinghai Province and flows from west to east through China's three major steps. The upstream and midstream are divided by Hekou Town, and the midstream and downstream are divided by Taohuayu. The main stream full length is 5464 kilometers, and the drainage area is about 752,000 square kilometers. The YRB has a large span, a wide area, and a large population. The natural environment and economic and social differences in the basin are significant. In 2019, the GDP of the eight provinces in the YRB (except Sichuan) accounted for $20.26 \%$ of the country's total GDP, and the population accounted for $23.31 \%$ of the total population in China. However, the level of economic development across regions is uneven, and the population density is increasing from upstream to downstream. In addition, although there are two national-level cities in the YRB, Zhengzhou and Xi'an, resource-based cities account for $28.63 \%$ of the national total, and old industrial bases account for $27.5 \%$ of the national total. At the same time, there are also "high energy consumption, high pollution, and low-level industries" and the imbalance of the urbanization rate has seriously affected the improvement of the green development level of cities in the YRB. The research scope is shown in Figure 4.

This paper takes 2008, 2013, and 2018 as the research time points; considering the availability of data, we exclude cities with missing data such as Yushu Tibetan Autonomous Prefecture and Haidong and selects 35 prefecture-level cities along the YRB as research samples. Basic data are obtained from "China City Statistical Yearbook," "China City Construction Statistical Yearbook," and statistical yearbooks of various cities. Some environmental indicators, such as days with good air quality in built-up areas, are derived from regional environmental bulletins and economic and social development bulletins. Some missing data use interpolation for makeup.

\section{Results}

\subsection{Analysis of the Spatiotemporal Pattern of the UGDI}

4.1.1. Comprehensive Evaluation of the UGDI. Table 2 shows that the UGDI of cities along the YRB is significantly different, the comprehensive UGDI is relatively low (0.2699-0.3799), the UGDI of cities with high administrative level and economic development level is relatively high, and the UGDI of provincial capitals such as Jinan, Zhengzhou, Hohhot, and Ordos have been in the forefront of the research period. Based on the measurement data of the UGDI in three years, from the perspective of the average value: horizontally, Jinan has the highest UGDI (0.6503), and Yuncheng has the lowest UGDI (0.2699), with a range value of 0.3875 . Vertically, the UGDI of 35 cities shows a slow upward trend. In 2013, it increased by $5.09 \%$ compared with 2008. In 2018, it has increased by $0.5 \%$ compared with 2013 . The 35 cities are further divided into three echelons: the first echelon is Jinan, Ordos, Zhengzhou, Hohhot, Lanzhou, Dongying, and Baotou; the UGDI is greater than 0.5000, accounting for $20 \%$; there are 17 cities in the third echelon, including Taian, Yinchuan, Zibo, Wuhai, Jining, Shizuishan, Binzhou, Luoyang, Dezhou, Wuzhong, Jiaozuo, Jiyuan, Zhongwei, Liaocheng, Xinxiang, Bayannaoer, and Linfen, with UGDI ranging from 0.3000 to 0.4999 , accounting for 48.57\%; the remaining 11 cities are in the third echelon, including Puyang, Kaifeng, Baiyin, Yan'an, Heze, Xinzhou, Sanmenxia, Weinan, Luliang, Yulin, and Yuncheng; and the UGDI is between $0.2000-0.2999$, accounting for $31.43 \%$.

4.1.2. Spatial Characteristics of UGDI. Figure 5 shows the UGDI of cities along the YRB varies greatly across regions, and the UGDI between cities has a strong imbalance. First, the number of cities with high green development level is generally increasing. There were 4 cities in 2008 and 6 cities in 2013 and 2018, and they were mainly concentrated in provincial capitals such as Lanzhou and Jinan, as well as cities with more developed economies. Compared with other cities in the region, these cities are driven by the advantages of natural location and policy and can obtain better development opportunities. It is easy to form a "siphon effect" in each region; advantageous resources and high-tech talents gather in provincial capitals to promote the optimization and upgrading of economic development methods, such as the transformation of economic development from labor-intensive to capital and technologyintensive, and the transformation of production input factors from labor and resources to capital and technology, which will reduce the pressure on the resource environment and labor costs, so that the UGDI can be maintained 
TABLe 1: Evaluation index system of green development.

\begin{tabular}{|c|c|c|c|c|}
\hline Target layer & Criterion layer & Index layer & Nature & Weight \\
\hline \multirow{23}{*}{ Green development } & \multirow{5}{*}{ Green growth } & GDP per capita & + & 0.0389 \\
\hline & & Proportion of tertiary industry in GDP & + & 0.0071 \\
\hline & & Sulfur dioxide emissions per unit GDP & - & 0.1747 \\
\hline & & Smoke (powder) dust emission per unit GDP & - & 0.1210 \\
\hline & & Wastewater discharge per unit GDP & - & 0.0477 \\
\hline & \multirow{6}{*}{ Green benefit } & Disposable income of urban residents per capita & + & 0.0040 \\
\hline & & Retail sales of consumer goods per capita & + & 0.0422 \\
\hline & & Proportion of science and education expenditures in GDP & + & 0.0196 \\
\hline & & Number of college students per 10,000 people & + & 0.1068 \\
\hline & & Books in public libraries per 100 people & + & 0.0597 \\
\hline & & Number of medical beds per 10,000 people in the city & + & 0.0102 \\
\hline & \multirow{5}{*}{ Green wealth } & Park green area per capita & + & 0.0162 \\
\hline & & Green coverage rate in built-up area & + & 0.0045 \\
\hline & & Number of days with good air quality in built-up areas & + & 0.0057 \\
\hline & & Industrial wastewater discharges per capita & - & 0.0429 \\
\hline & & Industrial sulfur dioxide emissions per capita & - & 0.2206 \\
\hline & \multirow{7}{*}{ Green governance } & Centralized treatment rate of urban domestic sewage & + & 0.0083 \\
\hline & & Harmless treatment rate of urban domestic waste & + & 0.0038 \\
\hline & & Comprehensive utilization rate of general industrial solid waste & + & 0.0109 \\
\hline & & Urban road area per capita & + & 0.0182 \\
\hline & & Buses per 10,000 urban residents & + & 0.0339 \\
\hline & & Urban water penetration rate & + & 0.0005 \\
\hline & & Urban gas penetration rate & + & 0.0027 \\
\hline
\end{tabular}

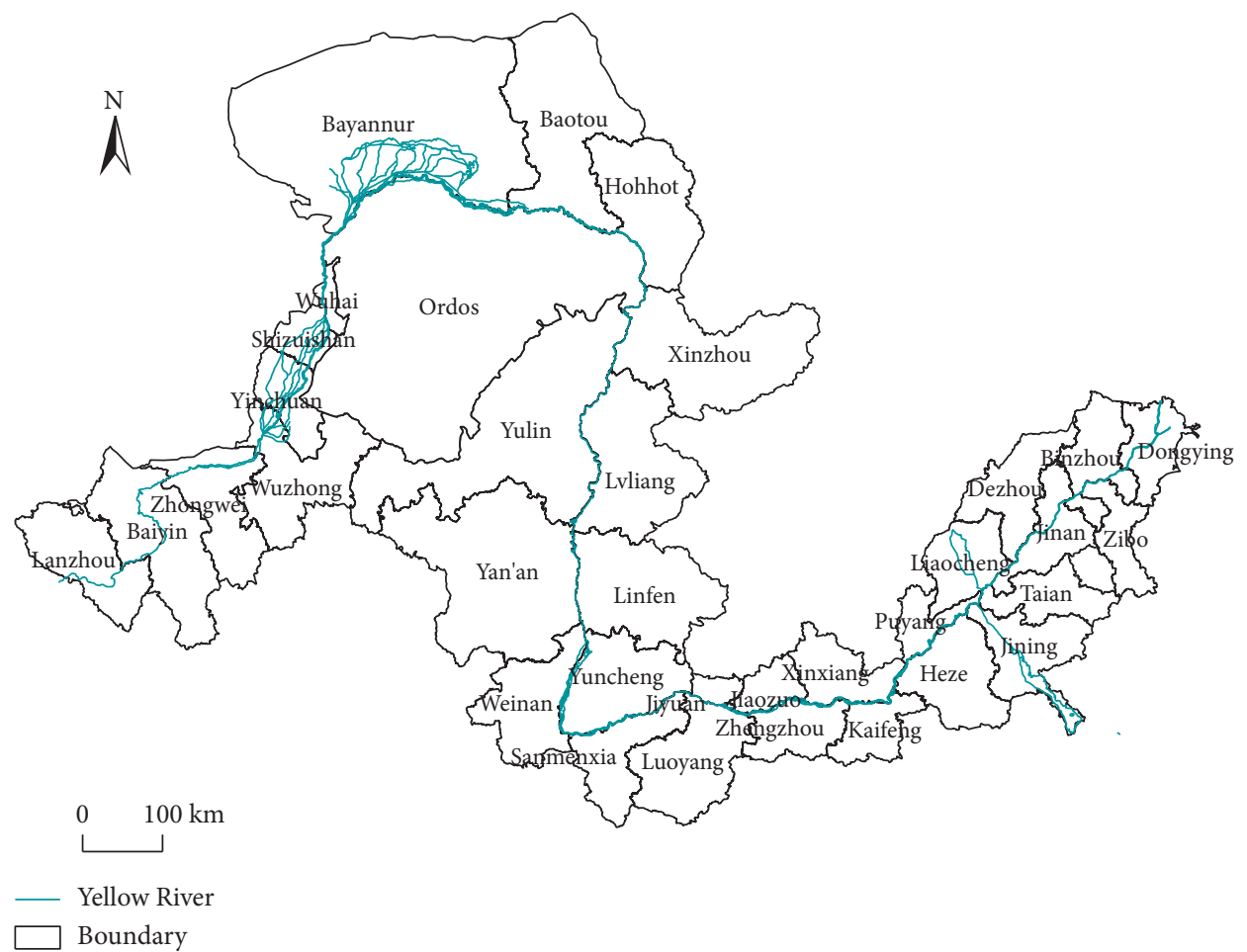

FIGURE 4: Sample area: the yellow river basin.

at a high level. Second, mid-high and mid-low level cities are mainly distributed around high-level cities, such as Shandong Peninsula with Jinan as the center and Central Plains with Zhengzhou as the center. These cities are obviously driven by regional central cities, which is conducive to promoting urban green development. Finally, low-level cities are widely distributed in the upper, middle, and lower reaches, such as Yulin, Lvliang, Weinan, Yan'an, and Puyang. Most of these cities are in the middle stage of industrialization, and there are problems such as single industrial structure, deterioration of ecological environment, and backward infrastructure construction. 
TABLE 2: The UGDI of cities along the YRB.

\begin{tabular}{|c|c|c|c|c|c|c|c|}
\hline \multirow{3}{*}{ City } & \multicolumn{6}{|c|}{ Year } & \multirow{3}{*}{ Average } \\
\hline & \multicolumn{2}{|c|}{2008} & \multicolumn{2}{|c|}{2013} & \multicolumn{2}{|c|}{2018} & \\
\hline & Value & Ranking & Value & Ranking & Value & Ranking & \\
\hline Jinan & 0.6209 & 1 & 0.6695 & 1 & 0.6604 & 1 & 0.6503 \\
\hline Ordos & 0.4273 & 9 & 0.6565 & 2 & 0.6244 & 2 & 0.5694 \\
\hline Zhengzhou & 0.4683 & 7 & 0.4681 & 8 & 0.5920 & 3 & 0.5095 \\
\hline Hohhot & 0.5908 & 2 & 0.6041 & 3 & 0.5716 & 4 & 0.5888 \\
\hline Lanzhou & 0.4918 & 5 & 0.4724 & 7 & 0.5568 & 5 & 0.5070 \\
\hline Dongying & 0.5392 & 4 & 0.5059 & 6 & 0.5346 & 6 & 0.5265 \\
\hline Baotou & 0.5537 & 3 & 0.5250 & 4 & 0.4885 & 7 & 0.5224 \\
\hline Taian & 0.4217 & 10 & 0.3992 & 10 & 0.4742 & 8 & 0.4317 \\
\hline Yinchuan & 0.4588 & 8 & 0.5164 & 5 & 0.4595 & 9 & 0.4782 \\
\hline Zibo & 0.4891 & 6 & 0.4500 & 9 & 0.4592 & 10 & 0.4661 \\
\hline Wuhai & 0.3157 & 19 & 0.3800 & 12 & 0.4421 & 11 & 0.3793 \\
\hline Jining & 0.3500 & 16 & 0.3436 & 15 & 0.3957 & 12 & 0.3631 \\
\hline Shizuishan & 0.3216 & 18 & 0.3322 & 17 & 0.3945 & 13 & 0.3494 \\
\hline Binzhou & 0.3745 & 12 & 0.3630 & 14 & 0.3698 & 14 & 0.3691 \\
\hline Luoyang & 0.2508 & 27 & 0.3076 & 22 & 0.3613 & 15 & 0.3066 \\
\hline Dezhou & 0.3510 & 15 & 0.3668 & 13 & 0.3346 & 16 & 0.3508 \\
\hline Wuzhong & 0.2736 & 26 & 0.3149 & 20 & 0.3335 & 17 & 0.3073 \\
\hline Jiaozuo & 0.3227 & 17 & 0.2960 & 24 & 0.3321 & 18 & 0.3169 \\
\hline Jiyuan & 0.3055 & 21 & 0.3809 & 11 & 0.3316 & 19 & 0.3393 \\
\hline Zhongwei & 0.3098 & 20 & 0.2904 & 27 & 0.3188 & 20 & 0.3063 \\
\hline Puyang & 0.2411 & 28 & 0.2667 & 31 & 0.3088 & 21 & 0.2722 \\
\hline Kaifeng & 0.3008 & 23 & 0.2691 & 30 & 0.3031 & 22 & 0.2910 \\
\hline Liaocheng & 0.3642 & 13 & 0.3436 & 16 & 0.3031 & 23 & 0.3370 \\
\hline Baiyin & 0.2352 & 29 & 0.2278 & 35 & 0.3027 & 24 & 0.2552 \\
\hline Xinxiang & 0.2986 & 24 & 0.3171 & 19 & 0.3003 & 25 & 0.3053 \\
\hline Yan'an & 0.2269 & 32 & 0.3254 & 18 & 0.2876 & 26 & 0.2800 \\
\hline Heze & 0.2326 & 30 & 0.2615 & 33 & 0.2815 & 27 & 0.2585 \\
\hline Xinzhou & 0.3011 & 22 & 0.2618 & 32 & 0.2700 & 28 & 0.2776 \\
\hline Sanmenxia & 0.2300 & 31 & 0.2945 & 25 & 0.2619 & 29 & 0.2621 \\
\hline Bayannaoer & 0.3577 & 14 & 0.2920 & 26 & 0.2567 & 30 & 0.3021 \\
\hline Weinan & 0.1772 & 35 & 0.2568 & 34 & 0.2482 & 31 & 0.2274 \\
\hline Lvliang & 0.2038 & 33 & 0.2742 & 28 & 0.2460 & 32 & 0.2413 \\
\hline Yulin & 0.2023 & 34 & 0.3106 & 21 & 0.2444 & 33 & 0.2524 \\
\hline Linfen & 0.3888 & 11 & 0.2730 & 29 & 0.2388 & 34 & 0.3002 \\
\hline Yuncheng & 0.2905 & 25 & 0.2991 & 23 & 0.2200 & 35 & 0.2699 \\
\hline Average & 0.3511 & - & 0.3690 & - & 0.3745 & - & - \\
\hline
\end{tabular}

4.1.3. Characteristics Analysis of Spatial Autocorrelation. According to the adjacency relationship between various cities, the global Moran's I index of the UGDI in three years were calculated based on the Queen's adjacency matrix (Table 3). The results show that the Moran's I index of UGDI along the YRB is greater than 0 . In 2008, it was 0.0351 , which passed the test at a significance level of 0.01 , in 2013 and 2018, it was 0.234 and 0.252 respectively, and both passed the test at a significance level of 0.05 , indicating that there is a significant positive spatial autocorrelation of urban green development along the YRB. In 2013, the Moran's I index decreased compared with 2008, and the correlation degree of urban green development weakened. The cities with higher (or lower) green development level changed from strong agglomeration to weak agglomeration. There was an increase in 2018 compared with 2013, with an increase in concentration. Overall, the Moran's I Index has declined, and the degree of green development agglomeration has undergone a transformation process of "strong agglomeration-weak agglomeration-stronger agglomeration." The correlation degree of green development among cities has weakened, while the overall difference increased.

In order to further reflect the spatial correlation of green development in cities, according to the spatial relationship between each city and surrounding cities in the study year, the local spatial autocorrelation LISA index in the GeoDa software is used to study the agglomeration and distribution status of the UGDI. The results of the LISA analysis (Table 4) further show that the green development along the YRB is unbalanced. First, the " $\mathrm{H}-\mathrm{H}$ " area of UGDI has gradually transformed from a massive distribution to a point-shaped distribution. From 2008 to 2018, Zibo was the only city in the "H-H" area. The reason is that Zibo is located in the economic circle of the provincial capital Jinan and is greatly influenced by the radiation of the provincial capital city cluster. The strategies of Jinan-Taian courbanization and Jinan-Zibo courbanization have accelerated the formation of a regional linkage development pattern, which is used in 


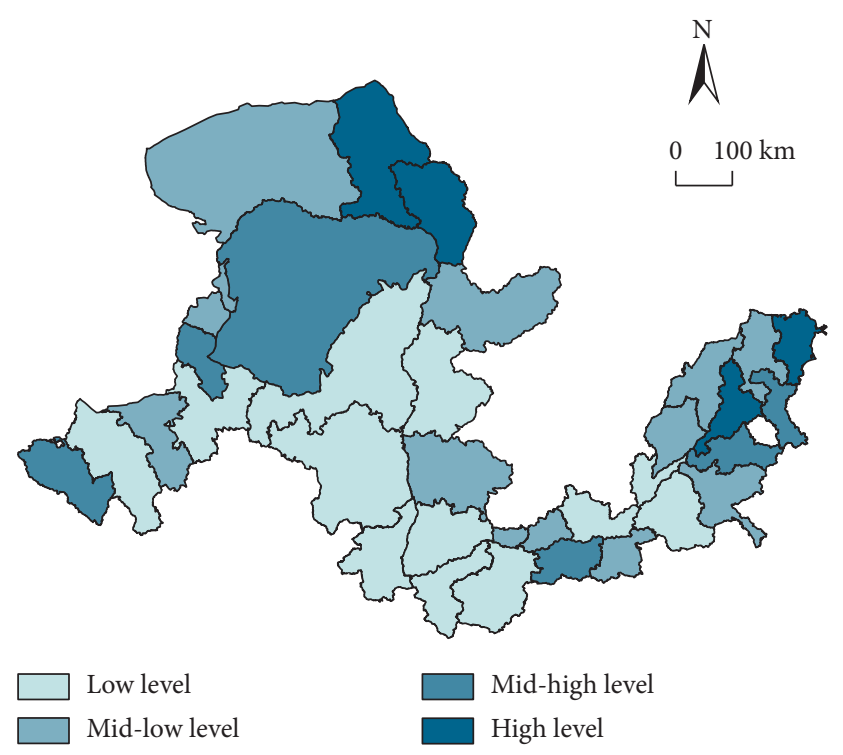

(a)

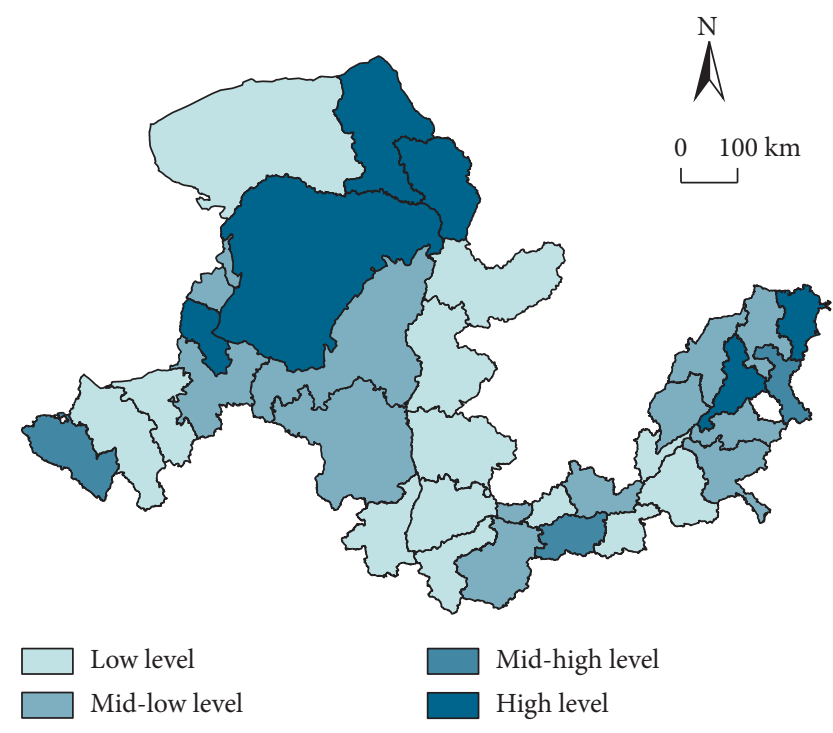

(b)

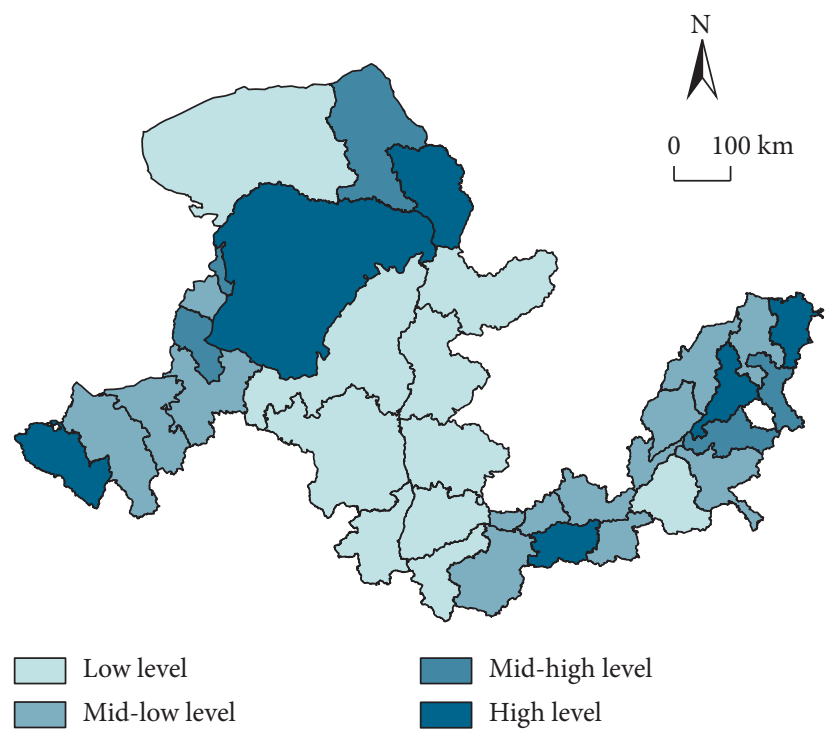

(c)

FIGURE 5: The spatial pattern of the UGDI in 2008, 2013, and 2018. (a) 2008. (b) 2013. (c) 2018.

TABLE 3: Global Moran's I index of the UGDI in 2008, 2013, and 2018.

\begin{tabular}{lccc}
\hline Year & Moran's $I$ & $p$ value & $z$-value \\
\hline 2008 & 0.351 & 0.001 & 3.290 \\
2013 & 0.234 & 0.020 & 2.313 \\
2018 & 0.252 & 0.014 & 2.435 \\
\hline
\end{tabular}

urban construction, ecological protection, and industrial development realizing comprehensive docking, coordinated protection, integrated development, and other aspects, thus forming a high-value area of the UGDI. Second, both "H-L" and " $\mathrm{L}-\mathrm{H}$ " cities are distributed in a dot pattern, such as " $\mathrm{H}$ L" cities Linfen and Lanzhou and "L-H" cities Bayannaoer and Binzhou, which are scattered in the YRB. Finally, the areas with "L-L" UGDI show obvious block-like agglomeration patterns. Shaanxi, Shanxi, and some cities in western Henan are the most concentrated, such as Yan'an, Weinan, Yuncheng, Linfen, and Sanmenxia. These cities are restricted by the "high energy consumption, high pollution, and low-level industrial and location conditions", and their economic development has encountered bottlenecks, making the UGDI always at a low level, thus forming a contiguous low-level region of green development. 
TABLE 4: Local LISA distribution of the UGDI in 2008, 2013, and 2018.

\begin{tabular}{ccccc}
\hline Year & H-H & H-L & L-H & L-L \\
\hline 2008 & $\begin{array}{c}\text { Bayannur, Baotou, Binzhou, } \\
\text { Zibo }\end{array}$ & Linfen & - & Yan'an, Yuncheng, Sanmenxia \\
2013 & Baotou, Zibo & Lanzhou & $\begin{array}{c}\text { Bayannur, Shizuishan, } \\
\text { Binzhou }\end{array}$ & $\begin{array}{c}\text { Zhongwei, Yan'an, Yuncheng, Linfen, Sanmenxia } \\
2018\end{array}$ \\
\hline
\end{tabular}

4.1.4. Global Trend Analysis. In order to show the spatial evolution trend of urban green development more intuitively, the trend analysis tool in ArcGIS 10.2 is used to describe the spatial distribution trend of urban green development along the YRB in 2008, 2013, and 2018, as shown in Figure 6. Among them, the $Z$ axis represents the UGDI, the line on the $X$ axis corresponds to the trend of the UGDI in the east-west direction, and the line on the $Y$ axis corresponds to the trend of the UGDI in the north-south direction. Overall, the curve change of the UGDI from 2008 to 2018 is small and remains stable. In the east-west direction, the curve shows an obvious " $U$ " distribution trend, indicating that the UGDI of the eastern and western cities along the YRB is high, while the central region forms a low value area of urban green development. Specifically, the UGDI show a trend of "high in the east and low in the west." In 2008 and 2018, there was a big difference in green development between the east and the west, while the difference in UGDI between the east and the west was small in 2013. In the north-south direction, the curve shows an obvious trend of "high in the north and low in the south," indicating that the UGDI in the north along the YRB is higher than that in the south, showing significant regional differences.

\subsection{Research on Spatial Differentiation of Influencing Factors}

4.2.1. Analysis Framework of Influencing Factors. Combing through the existing literature, it is found that the academic community has not yet established a recognized theory on the influence mechanism of urban green level, and the discussion on the influence factors of green development is mostly focused on three aspects: economic factors, geographical and environmental factors, and policy factors, while some scholars have added dummy variables such as financial crisis to the discussion of influence factors [37], to judge the impact of influencing factors on green development according to the regression model or obstacle degree model. The specific indicators are mainly selected from two aspects. First, they are directly selected from the evaluation indicators, such as GDP per capita, proportion of scientific and technological expenditure in GDP, and investment in environmental pollution control. Second, there are also scholars who break away from the evaluation indicators and reselect new driving factors, such as economic density, the proportion of the added value of the tertiary industry, and the amount of local water resources per capita. Referring to the existing research results of many scholars and combine the actual situation of the YRB, this paper selects variables from six aspects: economic development level (EDL) [38], industry advanced level (IAL) [39], urbanization level (UL) [40], environmental governance (EG) [38], technology level (TL) [40], and green infrastructure level (GIL) [41] and explores their impact degree on the green development of cities along the YRB (Table 5).

4.2.2. Regression Comparison of OLS and GWR Models. OLS and GWR model are mostly used to explore the spatial relationship of geographical phenomena. Using the UGDI as dependent variable and the above six influencing factors as independent variables, the OLS regression analysis was carried out by SPSS 25 software. The results (Table 6) of collinearity test showed that the variance inflation factor (VIF) of each influencing factor was less than 7.5, and the estimation equation did not appear variable redundancy. There was no multicollinearity among the factors, $R 2=0.827$, and the adjusted $R 2=0.790$. The model could explain most of the information. Before the GWR regression, it is necessary to test the spatial correlation of the UGDI. From the above analysis, it can be seen that the global Moran's $I$ index is greater than 0 and at least passes the significance test at the 0.05 level. There is spatial autocorrelation in urban green development, indicating that the traditional OLS regression has estimation bias. In addition, it can be seen from the regression results of the GWR model that $R 2$ and the adjusted $R 2$ are 0.864 and 0.794 , respectively, which are higher than those of the OLS model regression, indicating that the explanatory variables in the GWR model have stronger explanatory power on the explained variables and better goodness of fit. In summary, the GWR model is used to study the influencing factors of the UGDI in cities along the YRB, and ArcGIS 10.2 software is used to visualize the regression results.

\subsubsection{Spatial Heterogeneity of Influencing Factors}

(1) EDL. Figure 7 shows that there is a significant positive correlation between EDL and the UGDI; that is, the improvement of economic development is conducive to improving the urban green development level. From the perspective of supply, optimizing the economic growth mode and reforming the mechanism that hinders economic development in order to change the original crude production mode and inefficient resource allocation, improve supply efficiency and quality, so as to increase total factor productivity and the green development level. From the perspective of demand, with the progress of economy and society, people's demand has gradually increased from 


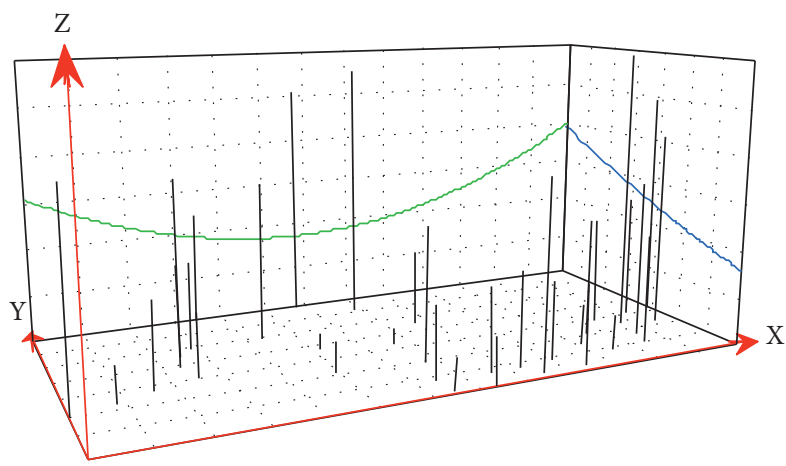

(a)

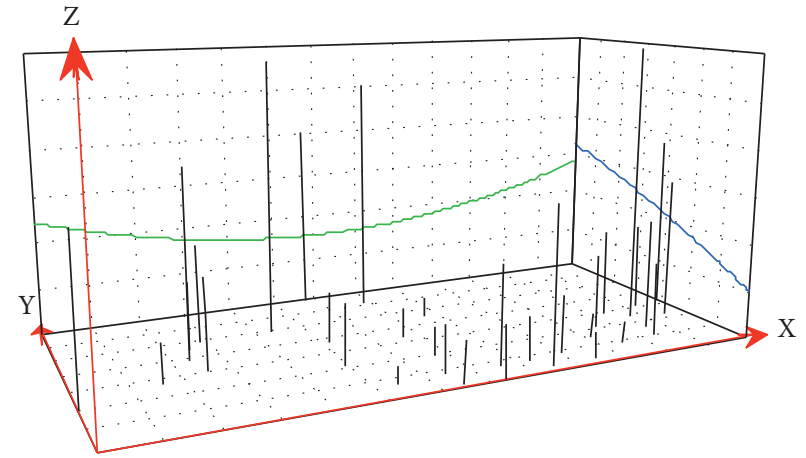

(b)

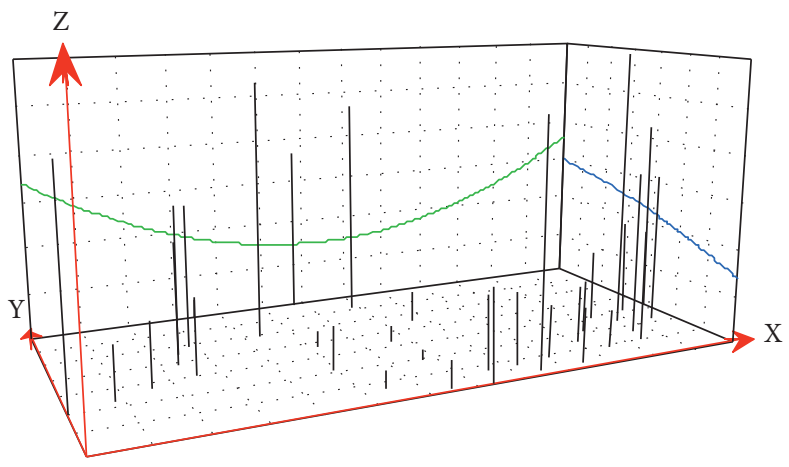

(c)

Figure 6: The spatial trend of the UGDI. (a) 2008. (b) 2013. (c) 2018.

TABLE 5: Selection of influencing factors for green development.

\begin{tabular}{lcc}
\hline Influencing factors & Variable & Calculation \\
\hline EDL & Economic density & $\begin{array}{c}\text { Regional GDP/total area } \\
\text { IAL }\end{array}$ \\
UL & Industrial structure advanced index & $\begin{array}{c}\text { Tertiary industry output value/second industry output } \\
\text { value }\end{array}$ \\
EG & $\begin{array}{c}\text { Proportion of urban population to total population } \\
\text { Energy saving and environmental protection }\end{array}$ & Urban population/total population of the region \\
TL & expenditure & - \\
GIL & Technology expenditure as a percentage of GDP & Technology expenditure/regional GDP \\
\hline
\end{tabular}

TABLE 6: Regression comparison between OLS and GWR models.

\begin{tabular}{cccccccc}
\hline & & & & \multicolumn{3}{c}{$R 2=0.827$} \\
OLS & EDL & IAL & UIF & EG & TL & GIL & Adj \\
& 2.0548 & 1.0655 & 2.6790 & 1.9722 & 1.0726 & 2.5147 & $R 2=0.790$ \\
\multirow{2}{*}{ GWR } & Neighbours & Residual squares & Effective number & Sigma & AICc & R2 & Adj $R 2$ \\
& 35 & 0.357 & 12.727 & 0.127 & -23.991 & 0.864 & 0.794 \\
\hline
\end{tabular}

material to high-quality environment and green products, which has become the internal driving force for the improvement of green development. At the same time, the impact of economic development level on the green development along the YRB has gradually weakened from east to west, indicating that economic development has improved the green development of eastern cities better than that of western cities. Areas with high coefficients are concentrated in the cities of Henan and Shandong in the eastern part of the YRB. Shandong and Henan have always been China's economically strong provinces. In 2018, the total GDP of Shandong and Henan ranked third and fifth respectively in the national rankings. For example, Henan is committed to adjusting the industrial structure. In 2008, the proportion of the secondary industry was $56.9 \%$, while in 2018 it dropped to $45.9 \%$, and the proportion of the tertiary industry rose from $28.6 \%$ in 2008 to $45.2 \%$ in 2018 . In addition, it used the policy dividends of Central Plains Economic Zone and Henan Free Trade Zone, relying on Internet technology, striving to build an agricultural-foodfiber industry chain and build an industrial development pattern led by energy conservation, environmental 


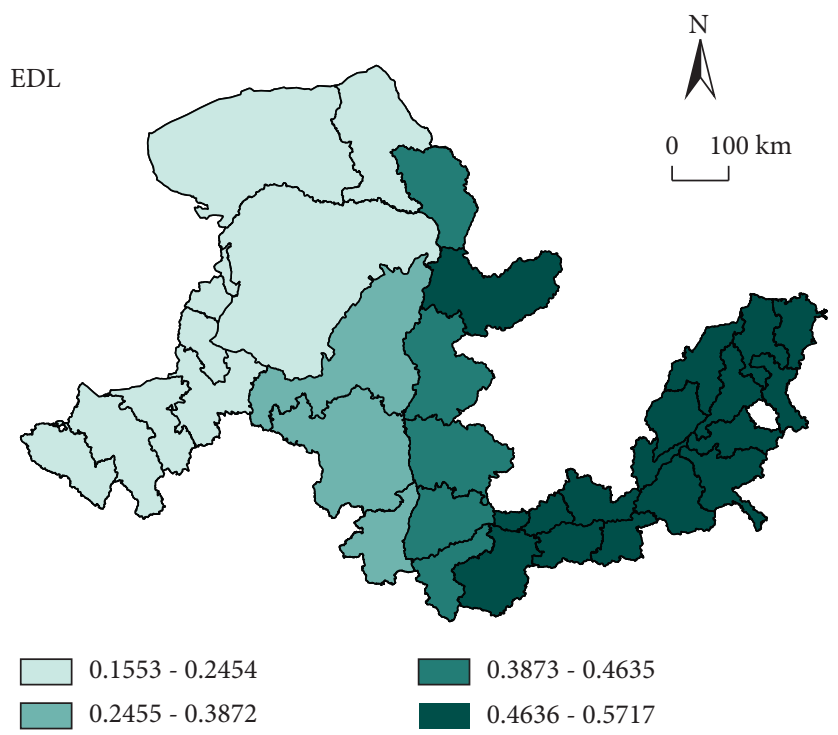

FIgURE 7: Spatial distribution of regression coefficient of the EDL on UGDI.

protection, biomedicine, and smart manufacturing. The industrial structure ratio has been improved, and the green economy has developed. Areas with low coefficients are concentrated in provinces and cities in the western part of the YRB, such as Gansu, Ningxia, some cities in Inner Mongolia Autonomous Region, and Weinan, Yan'an, and Yulin in Shaanxi Province. These areas are deep inland, and economic development is affected by natural location and has limited effects on the improvement of green development. In cities such as Yan'an, Weinan, and Yulin, traditional industries are the pillars of their economy. The tertiary industry has failed to truly become the driving force of economic development, lacking the power and ability to innovate new products, and the long-term dependence on resource input to stimulate economic growth has weakened. As a result, the significance of the promotion of green development by economic development is reduced.

(2) IAL. Figure 8 shows that there is a significant positive correlation between IAL and the UGDI, and the optimization of the industrial structure is conducive to the improvement of the urban green development along the YRB. The reason is that high-end and smart emerging industries have broken the previous structural restrictions, alleviating the pressure of extensive heavy chemical industries on the ecological environment under resource and environmental constraints and promoting the transformation of industrial structure to resource conservation and environmental friendliness, and effectively realize the mutual promotion and coordinated development of industrialization and green development. At the same time, the degree of impact of IAL on the green development along the YRB is spatially high on both sides and low in the central region. High-value areas are distributed in Lanzhou, Baiyin, and Yinchuan in the west of the YRB and most cities in Henan and Shandong in the east. Since the Ministry of Industry and Information Technology issued the "Approval of the Implementation Plan of the Pilot
Project of Industrial Green Transformation and Development in Lanzhou," Lanzhou has strengthened mechanism and model innovation and used market methods to promote regional industrial green development. Basically forming a strategic emerging industry system with high-end manufacturing, new energy, new materials, energy conservation, and environmental protection, to achieve new leadership in green and low-carbon industries, while Yinchuan pays more attention to technological innovation to promote industrial upgrading, vigorously implements industrial transformation and upgrading, and park transformation projects such as development and a strong city through science and technology have promoted the conversion of old and new drivers. Moreover, Shandong is guided by reform and innovation and promoted ecological construction to force economic transformation, which has gradually improved the development level of the industrial structure and promoted the continuous improvement of the green development level. The low-value areas are mainly distributed in Xinzhou, Luliang, and Sanmenxia in the midstream of the YRB. For a long time, the industrial structure of these cities has significant characteristics of heavy chemical industry. The industries dominated by coal mining and thermal power generation have obvious constraints on green development, coupled with long-term dependence on energy resources and greater resistance to the optimization and upgrading of traditional industries and the transformation of economic structure. The low-level industrial structure has little effect in driving green development. For example, in Luliang, which is rich in coal resources, the secondary industry is the pillar of economic development. In 2018, the secondary industry accounted for $61.4 \%$, and its coal output value accounted for $80 \%$ of the total industrial output value. For a long time, the coal chemical industry produced a large amount of soot and waste, which has not only increased environmental pollution, but also made green governance more difficult. 


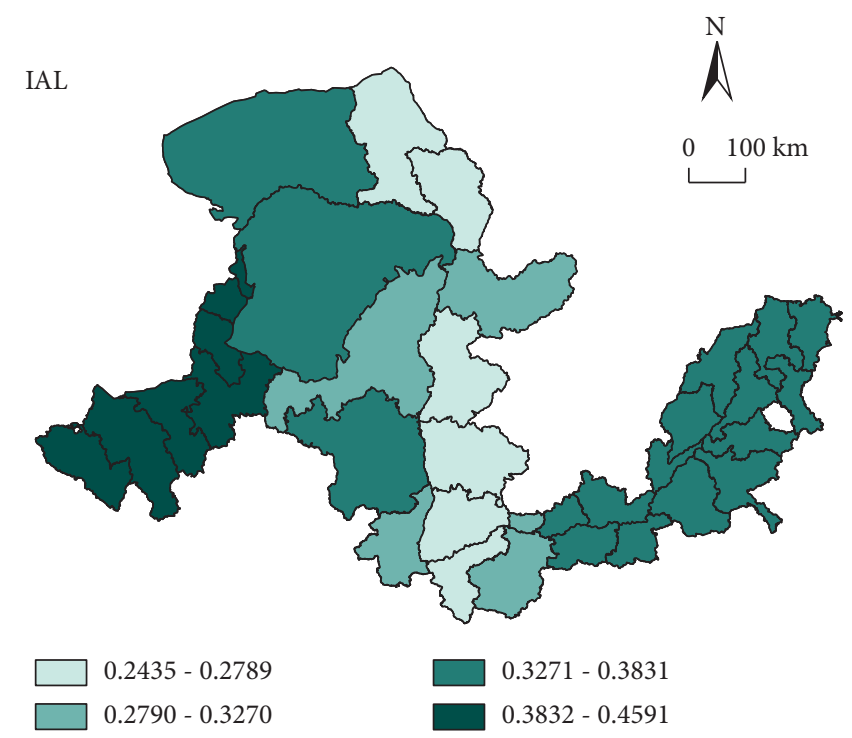

FIGURE 8: Spatial distribution of regression coefficient of the IAL on UGDI.

(3) UL. Figure 9 shows that there is a significant positive correlation between UL and the UGDI. The increase in the urbanization rate can actively promote the improvement of the urban green development and present the characteristics of "strong in east and weak in west"; that is, the promotion of green development in eastern cities is better than that of western cities. The reason is, first, as urbanization continues to improve, urban spatial layout and related supporting service functions have gradually improved, making urbanization more prominent as a carrier and platform for green development. Various urban development models explored in the process of urbanization, such as low carbon cities, green cities, smart cities, and livable cities will directly promote the improvement of green development. Second, the increase of urbanization means the expansion of urban population and the continuous agglomeration of industries, the release of the consumption potential of large-scale consumer groups in cities, which drives more diversification of consumption and upgrades of consumption structures, and huge urban public infrastructure, service facilities and housing demand stimulate urban economic development and indirectly promote the improvement of urban green development. However, it should be noted that a series of contradictions and problems will inevitably arise during the rapid development of urbanization, such as Baotou, Ordos, and Wuhai in the western part of the YRB. The higher urbanization rate is weaker than the eastern cities in driving the green development. The possible reason is that the urbanization development does not match the urban governance capabilities. The huge population size of the city puts greater pressure on the environment and weakens the driving effect of the improvement of the city's green development level. Therefore, it is necessary to correctly deal with the relationship between urbanization and green development, avoid related problems in time, and realize mutual promotion and integration of urbanization and green development.
(4) EG. Figure 10 shows that EG has different influences in different cities. Among them, the EG in the central and eastern regions is not conducive to the improvement of urban green development, while in the west, such as Lanzhou, Yinchuan, and Baotou, EG has a significant positive correlation with the green development, indicating that the impact of EG on the urban green development along the YRB is better than that of the central and eastern cities. In general, the government-led use of fiscal expenditure to solve ecological and environmental problems is an important method to improve the green development level. Through comprehensive treatment of air pollution, improvement of water quality, protection of the soil environment, cleaning of solid waste, and monitoring of the ecological environment, etc. cities can improve the ability of environmental pollution control and achieve the goal of resource-saving and environmentfriendly ecological civilization construction. For example, as an old industrial base, Baiyin has implemented the most stringent environmental protection system to promote environmental improvement, adopting ultra-low emission transformation of coal-fired units, strengthening motor vehicle pollution prevention, dust control, and strengthening law enforcement. A total of 3.4 billion $\mathrm{CNY}$ has been invested in pollution prevention and control in 2015. It has achieved a $100 \%$ compliance rate of drinking water and a $90.9 \%$ good air quality rate in 2018 . However, the EG in the midstream and downstream of the YRB is negatively correlated with the UGDI. This may be due to the fact that the ecological environment is fragile. Longterm overintensity development has caused severe environmental conditions. Soil erosion, the most obvious problem, cannot be completely solved. Overdraft of ecological carrying capacity has caused multiple environmental problems, relying solely on the limited energysaving and environmental protection expenditures in the government's finances cannot effectively control the 


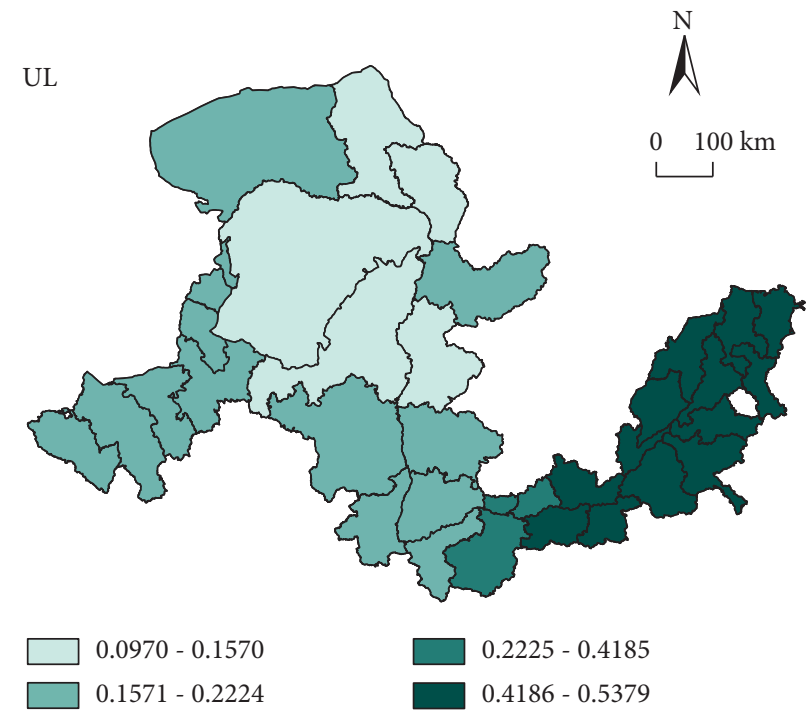

FIGURE 9: Spatial distribution of regression coefficient of the UL on UGDI.

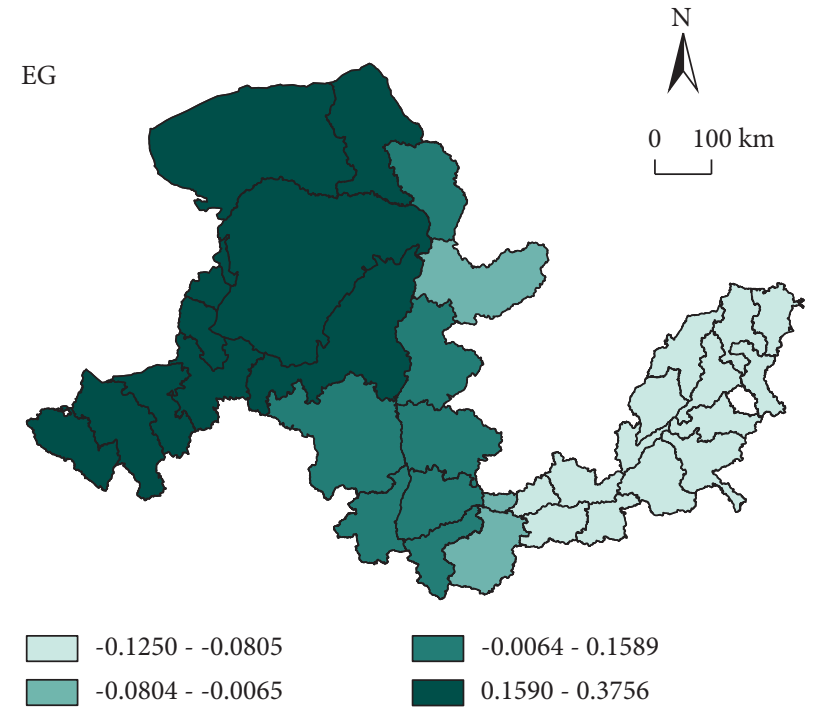

FIGURE 10: Spatial distribution of regression coefficient of the EG on UGDI.

chronic environmental problems in a short time. In addition, these regions are important manufacturing bases, and most of them undertake the transfer of high energyconsuming and high-polluting industries in the east. The population and industries are dense. The regions' competition makes energy conservation and environmental protection lack of regional linkage effects. The increase rate of green development brought by energy saving and environmental protection expenditure is less than the decrease rate of green development level caused by pollutant discharge.

(5) TL. Figure 11 shows that TL also has different influences in different cities, with the degree gradually weakening from west to east, indicating that the effect of TL on western cities is better than that of most eastern cities. The development of science and technology is a significant means to improve the comprehensive utilization efficiency of resources, increasing the input-output ratio and productivity. It can not only realize the optimization and upgrading of urban leading industries and promote the update and iteration of enterprise production technology, but also push forward the promotion and efficient use of new and clean energy, improve the long-existing coal-based energy resource consumption structure, and help to realize green production and green life. At the same time, scientific and technological development can enhance environmental pollution control, promote pollution control caused by production and life, and improve environmental management efficiency. For example, Lanzhou in the western part of the YRB is the political, economic, cultural, scientific, and educational center of Gansu Province, gathering a large number of high- 


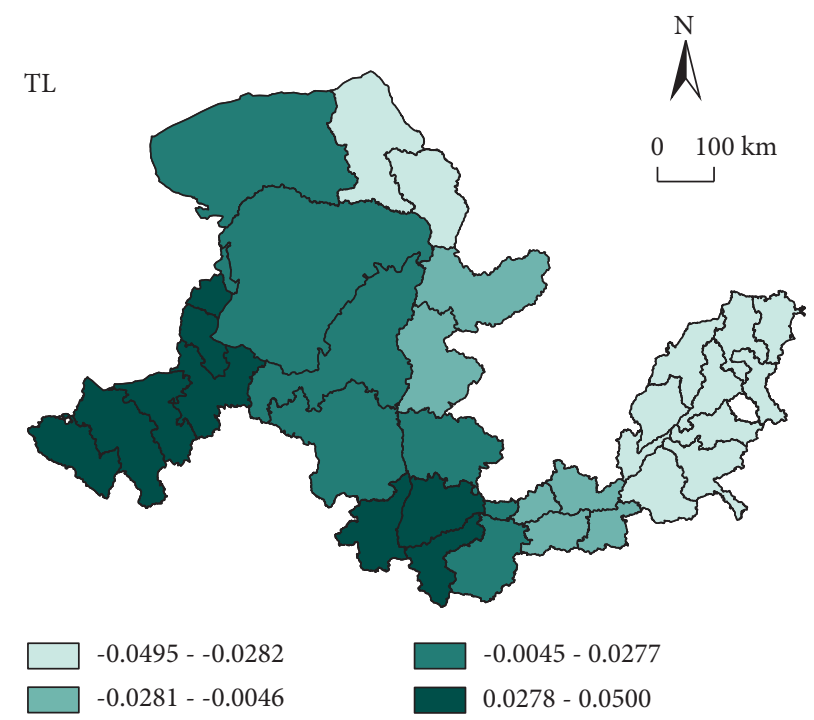

FIgURE 11: Spatial distribution of regression coefficient of the EDL on UGDI.

quality technological innovation elements and human resources. Since 2016, Lanzhou has achieved a total of 506 scientific and technological achievements transformation and developed 264 new products. In 2018, the city's scientific and technological progress contribution rate reached $57.1 \%$, which greatly promoted the green development. However, technological development has not played a role in improving the green development in most of the central and eastern cities along the YRB. Combined with the current strict environmental regulations in China, this is obviously contrary to the "Porter Hypothesis," which is a "green paradox." The possible reason is that, first, it is a long and complicated process from investment in scientific and technological development to the transformation of research results into practical applications, including technology research and development, talent training and introduction, and purchase of advanced scientific research equipment. This series of processes has a certain period of time, which leads to the inability of scientific and technological investment in promoting green development. Secondly, the fact that most cities have insufficient investment in science and technology research and development cannot be ignored. The lack of high-quality talents and the insufficiency of universities and research institutes have led to low efficiency in science and technology research and development. It is difficult to rely on science and technology to promote urban green in a short time. Finally, due to favorable location factors such as convenient transportation and labor intensiveness, the central and eastern parts of the YRB have undertaken a large number of industrial transfers from coastal areas. The scientific and technological research and development are mainly concentrated on the development of traditional secondary industries, rather than investment in green and cleaner production research and development, which has limited driving effect on the improvement of green development.
(6) GIL. Figure 12 shows that there is a significant positive correlation between GIL and the UGDI, and the increase of urban per capita public green area is conducive to the improvement of green development in the YRB. At the same time, the influence of GIL on the green development level shows the spatial distribution characteristics of high in the middle and low in the east and west, indicating that the effect of GIL on green development of central cities is better than that of eastern and western cities. Urban green infrastructure construction plays a role in green development from two aspects, improving urban ecological green quantity and inhibiting environmental deterioration. By building a green operation system of urban public infrastructure, and strengthening the supply of urban green facilities and ecological services, realizing the harmonious coexistence of "production-life-ecology" functions, so as to improve the urban ecological green quantity and meet people's increasing demands for green waters and mountains in the new era, it is the direct driving force for the improvement of the UGDI. Moreover, with the continuous improvement of urban green basic social level, the city's ability to manage ecological environment problems and energy resource utilization rate have been enhanced, especially for the Sanmenxia, Lvliang, and other resource-based cities in the middle of the YRB. The effect is particularly significant, and the green development has been improved from the inhibition of environmental degradation. At the same time, it should be noted that the impact of urban green infrastructure construction represented by per capita public green space area on cities in the east and west of the YRB is low. The possible reason is that the environmental problems caused by traditional heavy chemical industries are deeply rooted, and the ability to improve environmental conditions by simply increasing urban green space is weakened. Therefore, green development must be comprehensively addressed. 


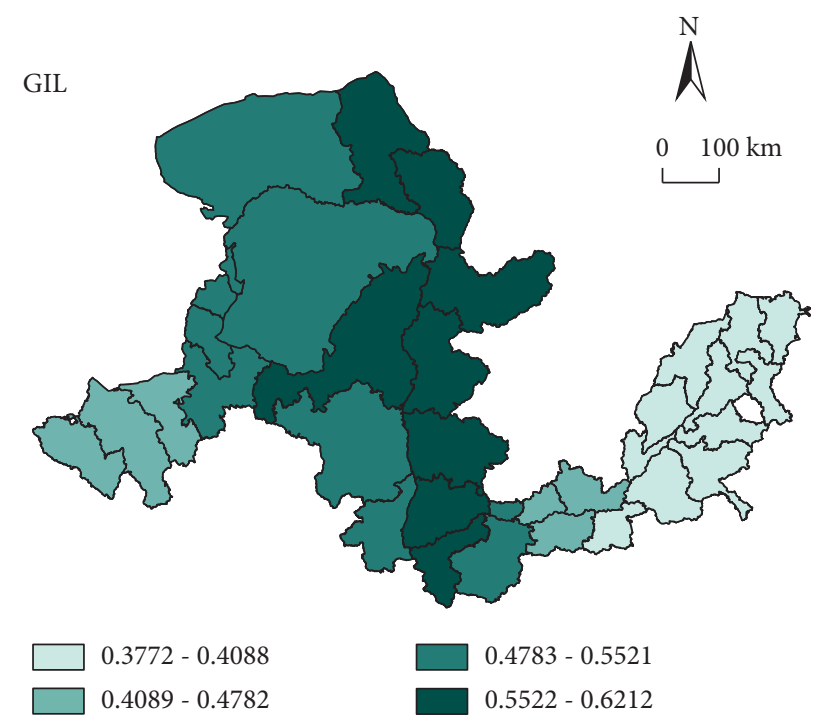

FIGURE 12: Spatial distribution of regression coefficient of the GIL on UGDI.

\section{Conclusions and Discussions}

\subsection{Conclusions}

(1) From 2008 to 2018, the UGDI of 35 cities in the YRB increased slowly, but it was still at a low level, and the green development level among cities was obviously unbalanced. Horizontally, the UGDI was hierarchical and can be divided into three echelons. The high-value areas of provincial capitals such as Jinan, Zhengzhou, and Lanzhou and the low-value depression areas in the central China are obvious.

(2) In 2008, 2013, and 2018, the global Moran's I index of urban green development in the YRB was greater than 0 , indicating that urban green development was significantly positive spatial autocorrelation. The Moran's $I$ index declined at the end of the period compared with the beginning, the degree of green development correlation between cities has weakened, and the overall difference has increased.

(3) The result of spatial differentiation showed that green development had great differences in the region. From the results of the global trend analysis, the UGDI showed a trend of "high in the east and west, low in the middle" and "high in the north and low in the south."

(4) There were significant regional differences in the impact of each influencing factor on the green development. Specifically, EDL, IAL, UL, and GIL had significant positive relationship with the UGDI, and the effects of EG and TL on the UGDI depend on cities, relating to the complex human and geographical factors of the YRB. Most of the space presented an irregular ladder-like distribution, with significant spatial heterogeneity.

\subsection{Policy Implications}

5.2.1. Innovate the Green Development Model and Enhance the Overall Economic Strength. On the one hand, strengthen cooperation in economic development between cities and give full play to the demonstration and driving role of the central city. Regional coordinated development is an inevitable trend to promote the green development of the YRB. To truly implement the national strategy of main functional zones, it is necessary to promote the free flow of green development factors, promote the rational division of labor and mutual promotion between regions, take the opportunity of central city agglomeration spillover and technology spillover as an opportunity to further promote the harmonious development of new industrialization, new urbanization, informatization, agricultural modernization and green, and combine the characteristics of cities in the YRB to build coordinated development new mechanism to serve the goal of improving green development.

On the other hand, innovate market decision mechanism to achieve efficient and rational allocation of resources. Correctly handle the relationship between the market and the government, give full play to the decisive role of the market in the allocation of resources, and establish crossbasin ecological resources and natural resources market pricing and trading mechanisms to achieve efficient and rational use of resources, through market and government incentives to guide enterprises and the public to participate in energy conservation and environmental protection, to achieve green development in the YRB. 


\subsubsection{Optimize the Industrial Structure and Vigorously Develop Green Industries.}

First, optimize the industrial layout of cities along the YRB. Speeding up the elimination of high energyconsuming, high-polluting, and low-profit enterprises and industries, especially in the central part of the YRB, requires active new industries and abandons long time dependent on backward industries, improves independent innovation capabilities, and cultivates emerging strategic industries such as renewable energy and new energy.

Second, speed up the green transformation of traditional industries and realize green transformation. Through the construction of a circular industrial chain to create a green industrial system, transform the extensive industrial structure; accelerate the promotion of green mining, clean production, discharge standards in the basin; and strive to achieve clean production process, harmless waste treatment, and resource utilization.

Finally, under the guidance of the green development concept of low consumption and low pollution, raise the entry threshold for high-pollution and highemission enterprises, formulate corresponding rewards and punishment systems for promoting industrial optimization and upgrading, actively guide developed regions to flow into high-tech industries, and avoid the YRB from becoming a "pollution refuge."

\subsubsection{Promote the Application of Green Technologies and} Improve Independent Innovation Capabilities. On the one hand, local governments should raise investment in science, technology, and education, especially in the central and eastern cities. They should strengthen support for green technological innovation and promote the establishment of a reasonable coordination and cooperation mechanism for industries, universities, and institutes, which are innovative, applicable, and cutting-edge. Provide strong support for sustainable green technologies, and provide policy incentives to companies that are conducive to the promotion of green development and application of technologies, optimize the resource allocation of technology and education related to green construction, increase the initiative and enthusiasm of enterprises, universities, and research institutes in green technology research, and attach importance to the transformation of research and technological achievements.

On the other hand, use energy-saving and emissionreduction technologies to achieve low pollution and low energy consumption in production and life, strengthen core technology research in the field of green production, and realize the technologicalization of green development. In addition, promote ecological restoration and technologicalization of environmental governance, and concentrate our efforts on the use of modern technology to control haze and other outstanding environmental problems.

\subsubsection{Promote the Construction of New Urbanization Based on Ecological Carrying Capacity.}

First, cities should not blindly pursue the agglomeration of population and wealth, but should strictly control the newly added urban construction land and realize the intensive use of urban land. In the process of population urbanization and land urbanization, it is necessary to adjust measures to local conditions. Innovate urban land transfer and management models based on the ecological carrying capacity of each city and region, where business is suitable for business, livable is suitable for living, and agriculture is suitable for farming, without blindly occupying ecological land, and reserve enough green space for green development. Initiating a comprehensive political, financial, and technological strategy to promote environmental protection, restore the relationship between cities and ecosystems, and create regenerative cities.

Second, promote the construction of endogenous mechanisms for urbanization. The construction of endogenous mechanisms is a complex systemic project that requires voluntary population migration as the core, new-type industrialization as the basis, market regulation as the leading factor, and government macrocontrol as the guarantee. Promote the rational and orderly coordination of various elements with green development.

5.2.5. Strengthening Infrastructure Construction and Improving Environmental Governance and Protection. Infrastructure construction plays a positive role in promoting the green development of the YRB. It is necessary to promote the balanced development of modern infrastructure and promote the continuous improvement of green level in different regions according to local conditions. In the construction of water resources infrastructure, water resources are taken as the maximum rigid constraint to strengthen the control of urban water and agricultural water. The most prominent problem in the Yellow River Basin is the contradiction of water resources. The problems such as more people and less water, less water and sediment, and water and sediment sources have long plagued the improvement of the greening level in the Yellow River Basin. Therefore, it is necessary to promote the construction of water conservancy facilities, focus on the development of water-saving agriculture along the Yellow River irrigation area, vigorously construct dryland terraces and silt dams in the middle and upper reaches, reasonably plan the water consumption of population, city and industry, adhere to the principle of determining city by water, determining land by water, determining people by water, determining production by water, and resolutely curb unreasonable water demand.

In the construction of ecological engineering facilities, strengthen the construction of regional ecological defense line, improve the coverage of urban public green space, increase urban ecological green quantity, and strengthen the 
construction of ecological pollution control projects, such as accelerating the construction of nonpoint source control facilities for domestic sewage and agricultural pollution in the Weihe River Basin and accelerating the construction of industrial pollution treatment projects in the Fenhe River Basin.

In the construction of transportation and communication projects, the western regions in the basin, such as Gansu and Ningxia, should speed up the improvement of transportation network, coordinate the construction of provincial boundaries and key nodes, and provide a convenient transportation foundation for green development. In addition, it should focus on strengthening the construction of information and communication infrastructure; accelerate the deployment of $5 \mathrm{G}$ network and cloud computing platform; provide digital, intelligent, and new green infrastructure system; and realize the deep integration of informatization and green construction.

\section{Data Availability}

The data used to support the findings of this study are available from the authors upon request.

\section{Conflicts of Interest}

The authors declare that they have no conflicts of interest.

\section{Acknowledgments}

This work was supported by grants from Support Plan for Scientific and Technological Innovation Talents in Henan Institutions of Higher Learning (Humanities and Social Sciences) (2018-cx-012); Training Plan for Key Young Teachers in Henan Institutions of Higher Learning (2018GGJS094); Good Scholar in Philosophy and Social Sciences in Henan Institutions of Higher Learning (2019YXXZ-20); and Philosophy and Social Science Innovation Team Building Program of Henan Universities (2021CXTD-12).

\section{References}

[1] X.-R. Wang, E. C.-M. Hui, C. Choguill, and S.-H. Jia, "The new urbanization policy in China: which way forward?" Habitat International, vol. 47, pp. 279-284, 2015.

[2] Y. Chen, M. Zhu, J. Lu, Q. Zhou, and W. Ma, "Evaluation of ecological city and analysis of obstacle factors under the background of high-quality development: taking cities in the Yellow River basin as examples," Ecological Indicators, vol. 118, Article ID 106771, 2020.

[3] Y. W. Chu, "China's new urbanization plan: progress and structural constraints," Cities, vol. 103, Article ID 102736, 2020.

[4] Y. Chen, X. Su, and Q. Zhou, "Study on the spatiotemporal evolution and influencing factors of urban resilience in the Yellow River basin," International Journal of Environmental Research and Public Health, vol. 18, no. 19, Article ID 10231, 2021.
[5] J. Colding and S. Barthel, "The potential of 'Urban Green Commons' in the resilience building of cities," Ecological Economics, vol. 86, pp. 156-166, 2013.

[6] K. Liu, X. Xie, and Q. Zhou, "Research on the influencing factors of urban ecological carrying capacity based on a multiscale geographic weighted regression model: evidence from China," Land, vol. 10, no. 12, p. 1313, 2021.

[7] L. Zhou, C. Zhou, L. Che, and B. Wang, "Spatio-temporal evolution and influencing factors of urban green development efficiency in China," Journal of Geographical Sciences, vol. 30, no. 5, pp. 724-742, 2020.

[8] Y. Guo, L. Tong, and L. Mei, "The effect of industrial agglomeration on green development efficiency in northeast China since the revitalization," Journal of Cleaner Production, vol. 258, Article ID 120584, 2020.

[9] X. Li, J. Du, and H. Long, "Understanding the green development behavior and performance of industrial enterprises (Gdbp-Ie): scale development and validation," International Journal of Environmental Research and Public Health, vol. 17, no. 5 , p. 1716, 2020.

[10] A. Huff and Y. Orengo, "Resource warfare, pacification and the spectacle of 'green' development: logics of violence in engineering extraction in southern Madagascar," Political Geography, vol. 81, Article ID 102195, 2020.

[11] Y. Li, Y. Chen, and Q. Li, "Assessment analysis of green development level based on S-type cloud model of beijingtianjin-hebei, China," Renewable and Sustainable Energy Reviews, vol. 133, Article ID 110245, 2020.

[12] H. E. Daly, "Toward some operational principles of sustainable development," Ecological Economics, vol. 2, no. 1, pp. 1-6, 1990.

[13] D. Pearce, A. Markandya, and E. Barbier, Blueprint for a Green Economy, pp. 7-15, Publications Limited, London, UK, 1989.

[14] B. Giddings, B. Hopwood, G. O'brien, and G. Environment, "Environment, economy and society: fitting them together into sustainable development," Sustainable Development, vol. 10, no. 4, pp. 187-196, 2002.

[15] M. Jänicke, "Green growth": from a growing eco-industry to economic sustainability," Energy Policy, vol. 48, pp. 13-21, 2012.

[16] Z. Li, W. Yang, C. Wang, Y. Zhang, and X. Yuan, "Guided high-quality development, resources, and environmental forcing in China's green development," Sustainability, vol. 11, no. 7, 1936 pages, 2019.

[17] M. Coli, E. Nissi, and A. Rapposelli, "Monitoring environmental efficiency: an application to Italian provinces," Environmental Modelling é Software, vol. 26, no. 1, pp. 38-43, 2011.

[18] R. Färe, S. Grosskopf, and F. Hernandez-Sancho, "Environmental performance: an index number approach," Resource and Energy Economics, vol. 26, no. 4, pp. 343-352, 2004.

[19] B. Zhu and M. Zhang, "Construction and demonstration of green development evaluation index system," Statistics \& Decisions, vol. 2019, p. 17, 2019.

[20] H. Zheng, Y. Wang, and B. Huang, "A research review on green development indicator system," J Ind Technol Econ, vol. 33, no. 2, pp. 142-152, 2013.

[21] C. Chen, J. Han, and P. Fan, "Measuring the level of industrial green development and exploring its influencing factors: empirical evidence from China's 30 provinces," Sustainability, vol. 8, no. 2, p. 153, 2016.

[22] C. Sun, Y. Tong, and W. Zou, "The evolution and a temporalspatial difference analysis of green development in China," Sustainable Cities and Society, vol. 41, pp. 52-61, 2018. 
[23] M. X. Wang, H. H. Zhao, J. X. Cui et al., "Evaluating green development level of nine cities within the pearl river delta, China," Journal of Cleaner Production, vol. 174, pp. 315-323, 2018.

[24] K. Shironitta, "Global structural changes and their implication for territorial Co 2 emissions," Journal of Economic Structures, vol. 5, no. 1, pp. 1-18, 2016.

[25] S. Honma and J.-L. Hu, "A panel data parametric frontier technique for measuring total-factor energy efficiency: an application to Japanese regions," Energy, vol. 78, pp. 732-739, 2014.

[26] S. S. Qin and X. X. Jin, "The analysis of the way to realize green development in China," Academic Journal of Zhongzhou, vol. 2016, no. 05, pp. 93-99, 2016.

[27] X. J. Li and A. P. He, "The restriction factor and path of green development," REFORM, vol. 6, no. 06, pp. 90-99, 2016.

[28] J. Yu, H. Shen, J. Gou, and X. Zhang, "The green environment measurement by entropy method: a study based on minnan coastal area in China," Journal of Coastal Research, vol. 103, no. SI, pp. 442-446, 2020.

[29] Q. Zhou, M. Zhu, Y. Qiao, X. Zhang, and J. Chen, "Achieving resilience through smart cities? Evidence from China," Habitat International, vol. 111, Article ID 102348, 2021.

[30] P. A. P. Moran, "Notes on continuous stochastic phenomena," Biometrika, vol. 37, no. 1/2, pp. 17-23, 1950.

[31] A. D. Cliff and J. K. Ord, "Spatial processes: models \& applications," Quarterly Review of Biology, vol. 38, no. 1, p. 287, 1982.

[32] L. Anselin, "Local indicators of spatial association-lisa," Geographical Analysis, vol. 27, no. 2, pp. 93-115, 1995.

[33] C. Brunsdon, A. S. Fotheringham, and M. E. Charlton, "Geographically weighted regression: a method for exploring spatial nonstationarity," Geographical Analysis, vol. 28, no. 4, pp. 281-298, 1996.

[34] C. G. Hou, J. L. Ren, Y. Chen, and S. F. Liu, "Spatial evolution and driving mechanism of China's greenization process," Scientia Geographica Sinica, vol. 38, no. 10, pp. 1589-1596, 2018.

[35] Y. Feng, X. Dong, X. Zhao, and A. Zhu, "Evaluation of urban green development transformation process for Chinese cities during 2005-2016," Journal of Cleaner Production, vol. 266, Article ID 121707, 2020.

[36] C. Hua, J. Chen, Z. Wan et al., "Evaluation and governance of green development practice of port: a sea port case of China," Journal of Cleaner Production, vol. 249, 2020.

[37] C. Feng, M. Wang, G. C. Liu, and J. B. Huang, "Green development performance and its influencing factors: a global perspective," Journal of Cleaner Production, vol. 144, pp. 323-333, 2017.

[38] S. Z. Tian and Y. J. Ding, "Greenization measurement of urban agglomeration in yangtze river delta and its influence factors: an empirical study based on the entropy-tobit model of 26 cities' panel data," Economic Geography, vol. 39, no. 9, pp. 94-103, 2019

[39] H. Cui and Z. Lui, "Spatial-temporal pattern and influencing factors of the urban green development efficiency in jing-jin-ji region of China," Polish Journal of Environmental Studies, vol. 30, p. 2, 2021.

[40] P. Li, L. Tong, Y. Guo, and F. Guo, "Spatial-temporal characteristics of green development efficiency and influencing factors in restricted development zones: a case study of jilin province, China," Chinese Geographical Science, vol. 30, no. 4, pp. 736-748, 2020.
[41] Y. Ma and Z. Huang, "Study on spatial-temporal evolution and measurement of green development index of urban agglomerations in the middle reaches of yangtze river-gwr model based," Ecology and Environmental Sciences, vol. 26, no. 5, pp. 794-807, 2017. 